\title{
EFEKTIVITAS MODEL EVALUASI PEMBELAJARAN AL-QURAN HADITS PADA SISWA MTS PONDOK PESANTREN PUTERI ATTAQWA DI MASA PANDEMI COVID-19
}

\author{
Taqiyuddin*, Ismail Marzuki** \\ *abangtaqie91@gmail.com,**ismailmarzuki@umt.ac.id \\ *Mahasiswa Magister PAI Program Pascasarjana, Universitas Muhammadiyah Tangerang \\ **Dosen Fakultas Agama Islam, Universitas Muhammadiyah Tangerang
}

\begin{abstract}
This study was conducted to determine the effectiveness of the Al Qur'an and Hadith learning evaluation model for students of MTs Pondok Pesantren Puteri Attaqwa during the Covid-19 pandemic. The method in this study uses descriptive qualitative techniques. The data in this study were obtained through interviews and analysis of the value of learning outcomes. The results of the study indicate that the evaluation model for learning the Qur'an and Hadith in MTS students at the Attaqwa Islamic Boarding School for Girls is not effective because it has various limitations.
\end{abstract}

Keywords: Learning Evaluation Model, Islamic Boarding School, Covid-19.

\section{A. PENDAhuluan}

Pembelajaran

adalah serangkaian proses belajar mengajar yang diorientasikan untuk mencapai tujuan pembelajaran (Anshori \& Bawani, 1991). Selain itu Pribadi (2009) mengatakan belajar merupakan kegiatan yang dilakukan seseorang agar dapat mencapai kompetensi yang diinginkan, melalui proses belajar seseorang dapat memperoleh pengetahuan, keterampilan, dan sikap yang lebih baik.

Setiap pembelajaran memiliki target atau tujuan yang ingin dicapai. Maka, untuk mengetahui pencapaian tujuan pembelajaran diperlukan evaluasi. Menurut Gronlund (dalam Purwanto, 2013) evaluasi pembelajaran ialah proses yang sistematis untuk menentukan atau membuat keputusan sampai sejauh mana tujuan-tujuan pembelajaran telah dicapai oleh siswa.
Sistem Pendidikan Nasional menggunakan Taksonomi Bloom untuk mengevaluasi hasil belajar. Bloom (dalam Sudjana, 2011) mengklasifikasikan hasil belajar menjadi tiga aspek, yaitu aspek kognitif, aspek afektif, dan aspek psikomotoris.

Aspek kognitif mencakup kegiatan mental (otak). Aspek kognitif dibagi menjadi enam bagian, yakni 1) Pengetahuan; 2) Pemahaman; 3) Penerapan/aplikasi; 4) Analisis; 5) Sisntesis; 6) Evaluasi. Aspek afektif ialah aspek yang berkaitan dengan sikap dan nilai, sikap seseorang dapat diramalkan perubahannya apabila ia telah memiliki penguasaan kognitif tingkat tinggi. Ada beberapa kategori aspek afektif, yaitu 1) Penerimaan; 2) Jawaban; 3) Penilaian; 4) Organisasi; 5) Karakteristik nilai/ pembentukan pola hidup. Sementara aspek psikomotoris adalah aspek yang berkaitan dengan 
keterampilan atau kemampuan bertindak setelah seseorang menerima pengalaman belajar tertentu.

Ketika Pandemi Covid-19 masuk ke Indonesia di awal maret 2020 aktivitas sekolah berubah dari sekolah dengan pertemuan tatap muka menjadi pembelajaran jarak jauh. Tak terkecuali yang terjadi di Pondok Pesantren Puteri Attaqwa. Sejak 21 maret 2020 santriwati dipulangkan untuk kemudian mengikuti pembelajaran jarak jauh. Tak hanya pembelajaran, evaluasi hasil belajar pun dilakukan dalam jaringan (internet).

Pondok Pesantren Puteri Attaqwa sebuah pondok pesantren khusus perempuan untuk tingkat Madrasah Tsanawiyah yang terletak di jalan KH. Mukmin Belendung Benda Kota Tangerang menjadi subyek untuk penelitian ini. Pondok Pesantren Puteri Attaqwa pada ujian Al Quran Hadits semester genap tahun ajaran 2019/2020 melakukan evaluasi pembelajaran melalui dalam jaringan (internet) menggunakan fasilitas aplikasi WhatsApp untuk memberikan soal untuk kemudian santriwati menyampaikan jawaban soal dengan cara memfoto jawaban soal yang telah ditulis.

Penelitian ini akan dilaksanakan menggunakan metode kualitatif deskriptif melalui wawancara dan analisa nilai hasil evaluasi pembelajaran. Tujuan penelitian ini untuk mengetahui efektivitas model evaluasi pembelajaran Al Quran Hadits pada siswa MTs Pondok Pesantren Puteri Attaqwa di masa pandemi covid19.

\section{B. METODE}

Metode yang digunakan dalam penelitian ini ialah metode penelitian kualitatif dengan pendekatan studi deskriptif. Pendekatan dalam penelitian ini menekankan pada aspek pendeskripsian temuan penelitian. Interpretasi penulis dalam penelitian ini berupaya sesuai dengan fakta yang terjadi di lapangan.

Teknik pengumpulan data yang dipergunakan dalam penelitian ini adalah wawancara dan analisa nilai hasil evaluasi pembelajaran Al Quran Hadits semester genap Tahun Ajaran 2019/2020. Wawancara dilaksanakan dengan melakukan tanya jawab dengan siswa dan guru terkait model evaluasi yang digunakan. Sementara analisa nilai hasil evaluasi pembelajaran dilakukan dengan menganalisa hasil laporan perkembangan evaluasi peserta didik. Data yang telah diperoleh dianalisis menggunakan Teknik analisis kualitatif deskriptif.

\section{HASIL DAN PEMBAHASAN}

Hasil dan pembahasan penelitian ini disesuaikan berdasarkan hasil fokus penelitian sebagaimana disebutkan pada bagian pendahuluan, yakni sebagai berikut:

1. Evaluasi Pembelajaran Al Quran Hadits Aspek Kognitif

Pada aspek kognitif Guru Al Quran Hadits Pondok Pesantren Puteri Attaqwa menggunakan intsrumen evaluasi pembelajaran berupa soal berbetuk essay. Soal berbetuk essay dipilih karena mampu menunjukkan pemahaman siswa akan pembelajaran sebab siswa akan mendeskripsikan pengetahuan. Seperti halnya yang dikatakan oleh Guru Al Quran Hadits di Pondok Pesantren Puteri Attaqwa, " soal berbentuk essay 
karena siswa dapat menuliskan jawaban soal sesuai pemahaman mereka."

Evaluasi aspek kognitif juga menggunakan instrumen ujian lisan. Berdasarkan wawancara kepada siswa ujian lisan dilaksanakan dengan cara video call untuk menghafal ayat ayat alquran dan beberapa hadits. Guru Al Quran Hadits Di Pondok Pesantren Puteri Attaqwa mengatakan, "ujian lisan menguji kemampuan menghafal siswa."

2. Evaluasi Pembelajaran Al Quran Hadits Aspek Afektif dan Spititual

Evaluasi pembelajaran pada aspek afektif dan spiritual menggunakan instrumen buku mutaba'ah atau buku laporan siswa. Siswa akan menuliskan kegiatan menghafal dan mengulang hafalan di buku mutaba'ah. Seperti yang dikatakan oleh salah seorang siswa, " setiap setelah menyetor hafalan saya akan menuliskannya di buku mutaba'ah lalu memfotonya dan kirim ke guru melalui jaringan pribadi di WhatsApp."

3. Evaluasi Pembelajaran Al Quran Hadits Aspek Psikomotorik

Pada evaluasi pembelajaran aspek psikomotorik menggunakan instrumen video call dan rekaman video siswa Ketika membaca ayat Al Quran. Guru akan menilai bacaan Al Quran kesesuaian dengan makhrorijul huruf dan tajwid. Seperti yang dikatakan oleh Guru Al Quran Hadits Di Pondok Pesantren Puteri Attaqwa, "saya akan menilai bacaan Al Quran siswa yang telah video call atau mengirimkan rekaman video."
Ada perubahan yang sangat signifikan pada saat sebelum ada pendemi dan siswa berada di Pondok Pesantren Puteri Attaqwa selama 24 jam dimana guru dan memperhatikan siswa lebih lama, guru dapat memberikan tambahan pengetahuan pada saat jam belajar malam. Sementara saat pandemi covid-19 waktu yang dimiliki hanya terbatas. Bahkan evaluasi pembelajaran pun memiliki keterbatasan.

Permasalahan evaluasi pembelajaran secara jarak jauh memunculkan kekhawatiran obyektivitas guru dalam memberikan nilai, pengawasan dalam pengerjaan ujian, serta proses pemahaman terhadap materi yang akan diujikan. Hal ini membuat evaluasi pembelajaran tidak efektif dan maksimal (Lubis, dkk. 2020).

Hal ini pun yang dikeluhkan oleh Guru Al Quran Hadits Di Pondok Pesantren Puteri Attaqwa, evaluasi pembelajaran secara daring membuat pengawasan ujian sedikit lemah, serta waktu pengerjaan soal yang tidak sama setiap siswa. Terlebih evaluasi pada aspek afektif, spiritual dan psikomotoris yang memiliki keterbatasan karena guru tidak dapat mengobservasi langsung.

Damayanthi (2020) mengatakan pembelajaran daring yang dilaksanakan memang cukup dapat menggantikan pembelajaran tatap muka, namun apabila dilihat dari efektivitas, pembelajaran daring belum mampu membuat tujuan pembelajaran tercapai. Ketidaksiapan siswa dan guru baik dari sisi kemampuan menggunakan teknologi maupun ketersediaan sarana pembelajaran yang memadai, koneksi jaringan internet yang buruk di tempat tinggal, biaya, dan belum mampunya 
siswa serta guru beradaptasi dengan metode pembelajaran yang baru untuk dapat meghadirkan kondisi kelas yang kondusif secara virtual menjadi faktor yang membuat pembelajaran daring maupun evaluasi pembelajaran secara daring belum efektif dilaksanakan.

\section{KESIMPULAN}

Model evaluasi pembelajaran Al Quran Hadits Pada Siswa MTs Pondok Pesantren Puteri Attaqwa di masa pandemi covid-19 secara daring dalam pelaksanaannya belum efektif dan maksimal karena memiliki berbagai macam keterbatasan.

\section{DAFTAR PUSTAKA}

Anshori, I., \& Bawani, I. (1991). Cendekiawan Muslim dalam Perspektif Pendidikan Islam. Surabaya: Bina Ilmu.

Damayanthi, A. (2020). Efektivitas Pembelajaran Daring di Masa Pandemi Covid-19 pada Perguruan Tinggi Keagamaan Katolik. Jurnal Educational Tecnology, 19(3).

Lubis, R.R., Enita, P., Marpaung, M.A.F., \& Harahap, R. (2020). Model Evaluasi Pembelajaran PAI Berbasis Daring di MTs Usman Syarif Medan selama Pandemi Covid-19. El-Buhuth 3(1).

Pribadi, B.A. (2009). Model Desain Sistem Pembelajaran. Jakarta: Dian Rakyat.
Purwanto. (2013). Evaluasi Hasil Belajar. Yogyakarta: Pustakan Pelajar.

Sudjana, N. (2011). Penilaian Hasil Proses Belajar Mengajar. Bandung: Remaja Rosdakarya. 